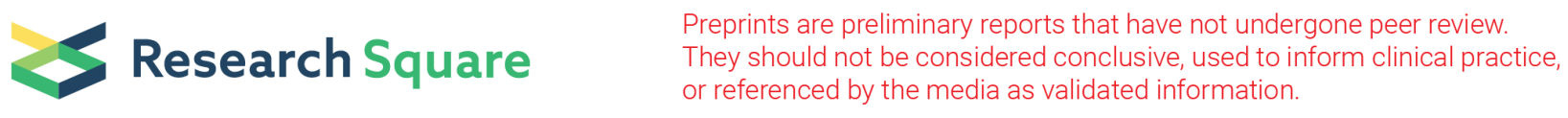

\title{
Spatial Distribution and Modeling of malnutrition among under-five Children in Ethiopia
}

Reta Lemessa ( $\square$ lemireta@yahoo.com)

Ambo University College of Natural and Computational Sciences https://orcid.org/0000-0003-4606-8716

Ararso Tafese

Ambo University College of Medicine and Public Health

Gudeta Aga

Ambo University

\section{Research article}

Keywords: Malnutrition, multilevel modeling, under-five children, Ethiopia

Posted Date: June 5th, 2020

DOI: https://doi.org/10.21203/rs.3.rs-32706/v1

License: @ (i) This work is licensed under a Creative Commons Attribution 4.0 International License. Read Full License 


\section{Abstract \\ Background}

Majority of this world is concerned by malnutrition. Ethiopia is one of the Sub Saharan African countries known by poverty, childhood diseases, high mortality and poor infrastructures and technology. The study aimed to examine differences within individuals and between clusters in nutritional status of under-five children and to identify socioeconomic factors using adequate nutrition of children in Ethiopia.

\section{Method:}

Data was obtained from Ethiopian 2019 Mini Demographic and Health Survey surveyed by Ethiopian Public Health Institute. A weighted sub- sample of 8768 under-five children was drawn from the dataset. Spatial statistics was used to analysis spatial variations of malnutrition of children in clusters of regional areas of Ethiopia. Multilevel modeling was used to look at demographic, socioeconomic factors at individuals and clusters levels.

\section{Result}

At national level the proportion of stunting, underweight and wasting among under-five children were 39.5 percent, 29.8 percent and 15.4 percent respectively. The Global Moran Index's value for children malnutrition result in Ethiopia was (for stunting I $=0.204, \mathrm{P}$-value $=<0.0001$, for underweight I $=0.195$, $\mathrm{P}$-value $=<$ 0.0001 and for wasting I $=0.152$, P-value $=<0.0001$ ). Spatial variability of malnutrition of under-five children across the clusters of Ethiopia observed. Result of heterogeneity between clusters obtained was $X^{2}=147.25, X^{2}=211.43 a n d X^{2}=201.43$ respectively for stunting, underweight and wasting with $\mathrm{P}=<$ 0.0001 providing evidences of variation among regional clusters with respect to the status of nutrition of under-five children. Multilevel model result revealed that high differences of malnutrition in individual households and regional clusters in the under-five children in Ethiopia.

\section{Conclusion}

The model showed that there were spatial variations in malnutrition among clusters in Ethiopia. Child age in month, breast feeding, family educational level, wealth index, place of residence, media access and region were highly significantly associated with childhood malnutrition. Inclusion of explanatory variables in multilevel model has shown that a significant impact on variation in malnutrition among individual households and regional clusters. Accessible resources, promoting education, use media to expand activities regarding nutritional and health services and through health workers and health institutions in Ethiopia is significant.

\section{Introduction}

Malnutrition is allied with the images of starving children who are suffering from severe acute malnutrition with their bellies bloated and their arms and legs pain fully boney. It can indeed refer to short-term acute malnutrition. But further malnutrition is chronic and lifelong, a highly preventable condition that begins in early childhood and continues into old age, divesting one generation and passing the miserable legacy on to the next. Malnutrition is a significant influence for maternal and child health and is the outcome of deficient of diet, poor care and infection diseases [1, 2].

According to World Health Organization (WHO) malnutrition indicated in three categories named as stunting, wasting and underweight considered by height for age, weight for age and weight for age indexed respectively [3]

Most under nutrition begins during pregnancy referred to as intrauterine growth retardation and the first two years of life, leading to higher infant mortality, stunting, low birth weight, and premature delivery. Each of indicators measures somewhat different aspects of nutritional status. Note that higher values of a $z$ score indicates better nutritional status and vice versa. Therefore, a decrease of z-scores indicates an increase in malnutrition [4].

Ethiopia has known shows potential progress in dropping levels of malnutrition over two past decades. However, the baseline levels of malnutrition remain so high that the country still needs to continue substantial investment in nutrition. According to Ethiopian Demographic and Health Survey (DHS), there is a substantial variation of under-five children nutrition in Ethiopia. For instance, there is regional variation in the prevalence of stunting in children; the estimated prevalence of chronic malnutrition is above the national average in Affar regional administration (49 percent), Tigray regional administration (44 percent), SNNP of Ethiopia (44 percent) and Amhara regional administration (42 percent) compared with a national average of 40 percent. Under nutrition of childhood in Ethiopia was declining between 2000 and 2019 years [5, 6]

Variations in under-five malnutrition proportion is associated with individuals socio-economic factors because it determines the amount of resources such as food, good sanitation, and health care that are available to infants and neglected temporal and geographic gradients and other variations in risk, in order to generate hypothesis towards the cause of malnutrition. For example, the exposure to stunting is higher in rural areas, among children because of mothers in urban have more awareness than in rural [7, 8]. Educated mothers and fathers have better health-seeking behavior for childhood illness as compared to uneducated which can help prevent malnutrition $[9,10]$.

Most of the countries in the world wide are affected by malnutrition. Stunting, underweight and wasting are reported to be serious problems affecting developing countries. In 2015, global data show that the prevalence of stunting, wasting and underweight were 37 percent, 8 percent and 15 percent respectively. Stunting among children of Africa has decreased in percentage terms from 38.3 percent to 30.3 percent over the same period, yet due to Loading [MathJax]/jax/output/CommonHTML/jax.js 
population highly growth, the real figure of stunted children has risen [1, 7]. The use of geospatial data shows that trends in malnutrition vary significantly within countries, with some areas experiencing increases and other areas declines.

Ethiopia is a country considered under developing country and the poorest country from Sub Saharan Africa. In empirical methods it can be examined that disparities in malnutrition of under-five children. Also investigating to what point the differences spatial distribution of malnutrition is influenced by socioeconomic factors. Thus, describing variations of malnutrition among children is important for scaling-up interventions. Therefore, this study aimed to investigate the existence of individual and regional variations in nutritional status of children as well as identifying socioeconomic factors influences nutritional status of under-five children in Ethiopia.

\section{Methods}

All regional parts of the country included in the study survey. The investigators used Ethiopian Mini DHS data that is national representative of the country. Mini DHS is the survey carried out between main DHS surveys by five years using multistage stratified sampling. Central Statistical Agency and Ethiopian public health institute were responsible. 8768 under five children were the subjects for analysis in this study because of the highest and long-lasting malnutrition-related risk associated with this age group. This sample size excludes all missing observations in both dependent and explanatory variables.

\section{Variables}

Response variable(s): Stunting (height for age), wasting (weight for height) and underweight (weight for age) were considered as dependent variables. These three indicators are standardized scores units used as references [3].

Explanatory variables: formal education for mothers and fathers, total number of living children, wealth index of households, marital status of mothers, child age, child sex, breastfeeding at time, visited by health workers during 12 months, residential type, region, availability of infrastructures like electricity, source of water, accessibility of media.

\section{Spatial Autocorrelation test}

Spatial statistics is the description and analysis of spatial variations in a given measurements of interests, using spatially referenced data. Two common measures of spatial autocorrelations are Moran's / and Gear's $C$ tests. The tests are used to show that amount of spatial distribution at all. Test for spatial autocorrelation are designed to count the point of clustering and to allow for statistical inference. The result of Moran's I indicates that statistical significance of spatial autocorrelation in model [11].

\section{Multilevel Modeling}

A multilevel logistic regression model also referred to as a hierarchal model, can account for lack of independence across levels of nested data (individuals within groups).

Multilevel modeling relaxes this assumption and allows the effects of these variables to vary across groups. It tolerates also not only independent variables at any level of a hierarchical structure, but also at least one random effect above level one [12].

\section{Multivariate Response Multilevel modeling}

Multivariate response multilevel models may possibly be necessary when one is interested in two or more outcomes measured on individuals within group. The researcher is interested in drawing conclusions about the degree to which the residual correlations depend on the individual and the group level; investigate specific effect of a covariate across two or more outcomes; and interest in conducting a single test of a joint effect of a covariate on two or more outcomes.

Then the two-level model can be written as;

$\log \left(\frac{\pi_{i j}}{1-\pi_{i j}}\right)=\beta_{0}+\beta_{i} X_{i}+u_{j}$

Where is the random effect at level-two. Equation (1) can be a standard logistic model without .

Therefore,

$\log \left(\frac{\pi_{i j}}{1-\pi_{i j}}\right)=\beta_{0 j}+\beta_{i} X_{i}$

(2)

and

$$
\beta_{0 j}=\beta_{0}+u_{j}
$$

(3)

Comparing to equations (2) and (3), equation (1) is said to be combined model [12]. 


\section{Result}

Result of Stata software showed that of the total 8768 respondents 3441 (3.2\%) stunted while 5327 (60.8\%) were normal and 2508 (28.6\%) were underweight while 6260 (71.4\%) were normal children.

Similarly 1425 (16.3 percent) were wasted while 7343 (83.7 percent) were normal children at the time of the survey.

From 39.5 percent of stunted children, more than half percent were aged less than 20 months years and also highly wasted and underweight children observed in this age group. This is viewing that as the age of children increasing the malnutrition is falling.

Mothers' education exposed the effects on nutritional status. The results mothers with no formal education 40.9 percent had had stunted children out of the given. Mothers' with secondary and higher education whose children were stunted 36.9 percent and 35.2 percent respectively. Thus, the effect of education might diminish when analysis is done based on the status of malnutrition.

The results revealed that the prevalence of stunting, wasting and underweight among the regions were variable with Tigray (48.1\%), Amhara and Somali regions $46.6 \%$ having highest proportion, while the lowest proportion of stunted was observed in Addis Ababa and Dire Dawa (24.9\% and $30.8 \%$ ) respectively. Somali and Afar regions were where highest proportion of wasted of children (23.9\% and $21.3 \%$ ) respectively while Addis Ababa and Harari were lowest proportion of wasted observed (6.8\% and 9.4\%) respectively. Likewise Somali and Afar confirmed that highest proportion of underweight (34.5\% and $34.1 \%$ ) respectively. Households who lived in rural area had highest proportion of stunted under-five children (39.4\%) while who lived in urban had lowest proportion of stunted under-five children (35.7\%).

Also those lived in rural area with highest proportion of wasted and underweight of children from the total were (23.9 percent and $37.1 \%)$ respectively while those lived in urban were 13.6 percent and 28.1 percent respectively. It is thought that exposure of media like radio, television and newspapers helps to improve health care and practiced of feeding. Accordingly, households who were not exposed to any kind of media (40.0\%) were found with stunted children than those who were exposed (35.5\%). Households who were not exposed to any kind of media ( $16.8 \%$ and $29.5 \%$ ) were found with more wasted and underweight children than those exposed to media (13.1\% and $23.4 \%)$ respectively. Some 42.5 percent of the households who had not been visited by health workers during last 12 months before the survey, while 37.1 percent of these who had been visited by health workers were have stunted under five-children.

Wealth index also showed effects on status of malnutrition of under-five children. From 39.5 percent of stunted children, 42.6 were poor, 38.8 percent were middle level and 32.0 percent were rich of under-five children. From total of wasted children, 20.0 percent were poor, 12.3 percent were middle level and 13.2 percent were rich of under-five children. Also highest prevalence of underweight children observed in those failed under poor, middle and rich status of the societies $(34.1 \%, 24.6 \%$ and $20.8 \%)$ respectively. 
Table 1

Descriptive analysis on some selected variables of malnutrition among under-five children, $n=8768$

\begin{tabular}{|c|c|c|c|c|c|c|c|c|c|}
\hline \multirow{2}{*}{$\begin{array}{l}\text { Variables } \\
\text { Stunt }\end{array}$} & \multicolumn{3}{|c|}{ Status of Stunting } & \multicolumn{3}{|c|}{ Status of Wasting } & \multicolumn{3}{|c|}{ Status of Underweight } \\
\hline & \multirow{2}{*}{$\begin{array}{l}\text { Normal } \\
\text { Count(\%) }\end{array}$} & \multirow{2}{*}{$\begin{array}{l}\text { |varvec } x^{2} \\
\text { (P value) }\end{array}$} & \multirow{2}{*}{$\begin{array}{l}\text { Wasting } \\
\text { Count (\%) }\end{array}$} & \multirow{2}{*}{$\begin{array}{l}\text { Normal } \\
\text { Count (\%) }\end{array}$} & \multirow{2}{*}{$\begin{array}{l}\text { Ivarvec } x^{2} \\
\text { (P value) }\end{array}$} & \multirow{2}{*}{$\begin{array}{l}\text { Underweight } \\
\text { Count (\%) }\end{array}$} & \multirow{2}{*}{$\begin{array}{l}\text { Normal } \\
\text { Count(\%) }\end{array}$} & \multirow{2}{*}{$\begin{array}{l}\text { |varvec } x^{2} \\
\text { (P value) }\end{array}$} & \multirow{6}{*}{10.703} \\
\hline Count (\%) & & & & & & & & & \\
\hline Age of & $1709(52.0 \%)$ & $1579(48.0 \%)$ & 364.245 & $771(23.4 \%)$ & $2517(76.6 \%)$ & $204.241(.000)$ & 1039(31.6\%) & $2249(68.4 \%)$ & \\
\hline 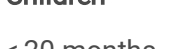 & $907(33.3 \%)$ & $1816(66.7 \%)$ & $(.000)$ & $295(10.8 \%)$ & $2428(89.2 \%)$ & & $827(30.0 \%)$ & 1930 & \\
\hline $\begin{array}{l}21-40 \\
\text { months }\end{array}$ & \multirow[t]{2}{*}{$825(29.9 \%)$} & \multirow[t]{2}{*}{ 1932(70.1\%) } & & \multirow[t]{2}{*}{$359(13.0 \%)$} & \multirow[t]{2}{*}{ 2398(87.0\%) } & & \multirow[t]{2}{*}{$751(27.6 \%)$} & $1972(72.4 \%)$ & \\
\hline $\begin{array}{l}41-59 \\
\text { months }\end{array}$ & & & & & & & & & \\
\hline \multirow{2}{*}{$\begin{array}{l}\text { Mothers } \\
\text { education }\end{array}$} & $2230(40.9 \%)$ & $3219(59.1 \%)$ & \multirow[t]{6}{*}{$17.71(.001)$} & $925(17.0 \%)$ & 4524(83.0\%) & \multirow[t]{6}{*}{$26.397(.000)$} & $1754(32.2 \%)$ & $3695(67.8 \%)$ & \multirow[t]{6}{*}{41.991} \\
\hline & $955(36.6 \%)$ & $1652(63.4 \%)$ & & $343(13.2 \%)$ & $2264(86.8 \%)$ & & $671(25.7 \%)$ & $1936(74.3 \%)$ & \\
\hline $\begin{array}{l}\text { No } \\
\text { education }\end{array}$ & $117(36.9 \%)$ & $200(63.1 \%)$ & & $44(13.9 \%)$ & $273(86.1 \%)$ & & $107(27.1 \%)$ & $288(72.9 \%)$ & \\
\hline Primary & $139(35.2 \%)$ & $25664.8 \%)$ & & $44(11.1 \%)$ & $351(88.9 \%)$ & & $76(24.0 \%)$ & $241(76.0 \%)$ & \\
\hline \multirow{2}{*}{\multicolumn{7}{|c|}{$\begin{array}{l}\text { Secondary } \\
\text { Higher }\end{array}$}} & & & \\
\hline & & & & & & & & & \\
\hline \multirow{2}{*}{$\begin{array}{l}\text { Fathers } \\
\text { education }\end{array}$} & 1721(38.5\%) & $2745(61.5 \%)$ & \multirow[t]{6}{*}{$48.205(.000)$} & $565(12.7 \%$ & 3901(87.3\%) & \multirow[t]{6}{*}{$97.406(.000)$} & $1189(26.6 \%)$ & $3277(51.6 \%)$ & 43.936 \\
\hline & $1149(40.7 \%)$ & $1674(59.3 \%)$ & & $457(16.2 \%)$ & $2366(83.8 \%)$ & & $916(32.4 \%)$ & $1907(67.6 \%)$ & \\
\hline $\begin{array}{l}\text { No } \\
\text { education }\end{array}$ & $256(40.1 \%)$ & $385(59.9 \%)$ & & 165(19.7\%) & $671(80.3 \%)$ & & $279(33.4 \%)$ & $557(66.6 \%)$ & \\
\hline Primary & $313(37.4 \%)$ & $523(62.6 \%)$ & & $169(26.3 \%)$ & $474(73.7 \%)$ & & $224(34.8 \%)$ & $419(65.2 \%)$ & \\
\hline Secondary & & & & & & & & & \\
\hline Higher & & & & & & & & & \\
\hline Region & $448(48.1 \%)$ & $483(51.9 \%)$ & $146.895(0.00)$ & 144(15.5\%) & 787(84.5\%) & $117.510(0.000)$ & $273(29.3 \%)$ & 658(70.7\%) & 131.11 \\
\hline Tigray & $314(38.2 \%)$ & $507(61.8 \%)$ & & $175(21.3 \%)$ & $646(78.7 \%)$ & & $280(34.1 \%)$ & $541(65.9 \%)$ & \\
\hline Afar & $410(46.6 \%)$ & $470(53.4 \%)$ & & $130(14.8 \%)$ & $750(85.2 \%)$ & & $255(29.0 \%)$ & $625(71.0 \%)$ & \\
\hline Amhara & $502(36.8 \%)$ & $863(63.2 \%)$ & & $222(16.3 \%)$ & 1143(83.7\%) & & $397(29.1 \%)$ & $968(70.9 \%)$ & \\
\hline Oromia & $531(46.6 \%)$ & $609(53.4 \%)$ & & 172(23.9\%) & 868(76.1\%) & & 393(34.5\%) & $747(65.5 \%)$ & \\
\hline Somali & $240(33.2 \%)$ & $482(66.8 \%)$ & & $90(12.5 \%)$ & 632(87.5\%) & & $211(29.2 \%)$ & $511(70.8 \%)$ & \\
\hline Benishangul & $420(38.6 \%)$ & $667(61.4 \%)$ & & $175(16.1 \%)$ & 912(83.9\%) & & $313(28.8 \%)$ & 774(71.2\%) & \\
\hline SNNP & 191(34.6\%) & $361(65.4 \%)$ & & $91(16.1 \%)$ & $461(83.5 \%)$ & & $157(28.4 \%)$ & $395(71.6 \%)$ & \\
\hline Gambela & $157(34.4 \%)$ & $299(65.6 \%)$ & & $43(9.4 \%)$ & $413(90.6 \%)$ & & $123(27.0 \%)$ & $333(73.0 \%)$ & \\
\hline Harar & $99(24.9 \%)$ & $298(75.1 \%)$ & & $27(6.8 \%)$ & $370(93.2 \%)$ & & $43(10.8 \%)$ & $354(89.2 \%)$ & \\
\hline $\begin{array}{l}\text { Addis } \\
\text { Ababa }\end{array}$ & 129(30.8\%) & $288(69.1 \%)$ & & $56(13.4 \%)$ & $361(86.6 \%)$ & & $63(15.1 \%)$ & 354 (84.9\%) & \\
\hline Dire Dawa & & & & & & & & & \\
\hline Place of & $367(35.7 \%)$ & $1037(64.3 \%)$ & $85.838(.000)$ & $220(13.6 \%)$ & 1394(86.4\%) & $108.345(.000)$ & $453(28.1 \%)$ & $1160(14.0 \%)$ & 51.674 \\
\hline Urban & 2817(39.4\%) & $\begin{array}{l}4338 \\
(60.6 \%)\end{array}$ & & $1710(23.9 \%)$ & $5445(76.1 \%)$ & & 2655(37.1\%) & $4500(62.9 \%)$ & \\
\hline Rural & & & & & & & & & \\
\hline $\begin{array}{l}\text { Exposure to } \\
\text { Media }\end{array}$ & $2985(40.0 \%)$ & $4490(60.0 \%)$ & $10.067(.001)$ & $1255(16.8 \%)$ & 6220(83.2\%) & $10.740(0.004)$ & 2206(29.5\%) & $5269(70.5 \%)$ & 20.450 \\
\hline Not at all & $456(35.3 \%)$ & $837(64.7 \%)$ & & $170(13.1 \%)$ & 1123(86.9\%) & & $302(23.4 \%)$ & $991(76.6 \%)$ & \\
\hline $\begin{array}{l}\text { At least } \\
\text { once a week }\end{array}$ & & & & & & & & & \\
\hline
\end{tabular}




\begin{tabular}{|c|c|c|c|c|c|c|c|c|c|}
\hline \multirow{3}{*}{$\begin{array}{l}\text { Variables } \\
\text { Visited by } \\
\text { HEW } \\
\text { within12 } \\
\text { months }\end{array}$} & \multicolumn{3}{|c|}{ Status of Stunting } & \multicolumn{3}{|c|}{ Status of Wasting } & \multicolumn{3}{|c|}{ Status of Underweight } \\
\hline & $2601(42.5 \%)$ & $3519(57.5 \%)$ & $4.313(0.020)$ & $947(15.5 \%)$ & $5173(84.5 \%)$ & $5.111(0.013)$ & 1778(29.1\%) & $4342(70.9 \%)$ & 4.648(. \\
\hline & $982(37.1 \%)$ & $1666(62.9 \%)$ & & $409(15.4 \%)$ & 2239(84.6\%) & & $830(31.3 \%)$ & $1818(68.7 \%)$ & \\
\hline \multicolumn{10}{|l|}{ No } \\
\hline \multicolumn{10}{|l|}{ Yes } \\
\hline \multirow{2}{*}{$\begin{array}{l}\text { Wealth } \\
\text { index }\end{array}$} & $1819(42.6 \%)$ & $2453(57.4 \%)$ & $59.880(0.000)$ & $856(20.0 \%)$ & $3416(80.0 \%)$ & $88.256(0.000)$ & $1471(34.4 \%)$ & $2801(65.6 \%)$ & 40.675 \\
\hline & 1043(38.8\%) & $1644(61.2 \%)$ & & $331(12.3 \%)$ & $2356(87.7 \%)$ & & $660(24.6 \%)$ & $2027(75.4 \%)$ & 000) \\
\hline Middle & $579(32.0 \%)$ & $1230(68.0 \%)$ & & $238(13.2 \%)$ & $1571(86.8 \%)$ & & $377(20.8 \%)$ & $1432(79.2 \%)$ & \\
\hline Rich & & & & & & & & & \\
\hline
\end{tabular}

\section{Spatial Data Analysis}

Global spatial autocorrelation was assessed using the Global Moran's / statistic (Moran's $)$ to evaluate whether the pattern was clustered, dispersed or random across the study area using ArcGIS version 10.3.

A positive value for Moran's index indicates a cluster pattern of childhood malnutrition. The result of Global Moran index value of malnutrition of children in Ethiopia (for stunting $I=0.204$, P-value $<0.0001$, for wasting $I=0.152$, P-value $=<0.0001$ and for underweight $I=0.195, P$-value $=<0.001$ ). These results indicate that there was a positive spatial autocorrelation or cluster adjacent having similarities in the prevalence of child malnutrition. In other word, we can say that the neighboring clusters influenced the prevalence of child malnutrition in Ethiopia.

A further peak is spatial mapping which is used to reveals variation across regions of Ethiopia. The geographical distribution of the indexes of the stunting (a), underweight (b) and wasting (c) displayed in Fig. 2 shows regionally spatial pattern. In view of that highest rate of stunting observed in Tigray, Amahar and Somali. Afar and Somali had the highest rates of underweight and wasting in the under-five children. Generally the result reveals that some Northern and Eastern part of the country had higher malnutrition proportion than central south-west regions.

\section{Multivariate Multilevel Regression Model}

To identify determinant factors of child malnutrition, a two level mixed effects logistic regression analysis was used. The intercept only model (empty model) was constructed without determinant factors to check the application of multilevel analysis to the data set. This model allows us to evaluate the extent of cluster variation influencing child nutritional status. In model two, only individual-level determinants factors were included and in model three, only cluster level determinants were included. The level of heterogeneity was evaluated at each model.

The data was tested to determine whether there is heterogeneity between clusters. The result of chi square were $147.28,211.55$ and 201.43 respectively for stunting, wasting and underweight with $p<0.0001$ providing evidence of heterogeneity among clusters with respect to the status of nutrition of under-five children (Table 2). 
Table 2

Estimates for variance components model for Stunting, Wasting and Underweight.

\begin{tabular}{|c|c|c|c|c|c|c|}
\hline Response variable & Indicators & OR & S.E. & Z-value & P-value & {$[95 \% \mathrm{Cl}]$} \\
\hline \multirow[t]{4}{*}{ Stunting } & $\beta_{0}=$ intercept & 1.580 & 0.0512 & 14.03 & 0.000 & 1.4 .7891 .680 \\
\hline & $\operatorname{var}\left(U_{o j}\right)=\delta_{0}^{2}$ & 0.295 & 0.0405 & & & 0.2260 .386 \\
\hline & $\begin{array}{l}\text { Deviance-based } \\
\text { chi-square }\end{array}$ & 147.25 & & & $<0.0001$ & \\
\hline & ICC & 0.082 & 0.011 & & & 0.0640 .105 \\
\hline \multirow[t]{4}{*}{ Wasting } & $\beta_{0}=$ intercept & 6.240 & 0.308 & 37.14 & 0.000 & 5.6706 .880 \\
\hline & $\operatorname{var}\left(U_{o j}\right)=\delta_{0}^{2}$ & 0.624 & 0.0798 & & & 0.4850 .801 \\
\hline & $\begin{array}{l}\text { Deviance-based } \\
\text { chi-square }\end{array}$ & 211.55 & & & $<0.0001$ & \\
\hline & ICC & 0.117 & 0.016 & & & 0.0890 .152 \\
\hline \multirow[t]{4}{*}{ Underweight } & $\beta_{0}=$ intercept & 2.717 & 0.1030 & 26.49 & 0.000 & 2.5232 .925 \\
\hline & $\operatorname{var}\left(U_{o j}\right)=\delta_{0}^{2}$ & 0.411 & 0.0498 & & & 0.2950 .492 \\
\hline & $\begin{array}{l}\text { Deviance-based } \\
\text { chi-square }\end{array}$ & 201.43 & & & $<0.0001$ & \\
\hline & ICC & 0.104 & 0.012 & & & 0.0820 .130 \\
\hline
\end{tabular}

From Table 2 we observe that the result estimated intra class correlation (ICC) used to assess the variation by levels and the values which is different from zero indicates that appropriateness of multilevel modeling analysis [14]. Thus the computed ICC $=0.082$ shows that 8.20 percent of the variation in the stunting under-five children can be explained by cluster (level two). The remaining 91.8 percent of the variation of stunting under-five children is explained within the same cluster. Likewise the ICC for wasting and underweight were 11.7 and 10.4 percent of variation between clusters (Table 2).

\section{Discussion}

In model two individual factors included and in model three cluster level factors are included (Table 3).

The model revealed that the likelihood of malnutrition status of under-five children was high in those not breastfeeding mothers during the survey done compared to those breastfeeding mothers $(\mathrm{OR}=1.22 ; 95 \% \mathrm{Cl}: 1.10-1.37, \mathrm{OR}=1.15 ; 95 \% \mathrm{Cl}: 1.03-1.29$ and $\mathrm{OR}=1.13 ; 95 \% \mathrm{Cl}$ : $0.97-1.32)$ for stunting, wasting and underweight respectively.

Under-five children whose mothers completed secondary and higher education were 36 percent and 54 percent less likely affected by stunting compared to mothers with no formal education $(\mathrm{OR}=0.36 ; 95 \% \mathrm{Cl}: 0.22-0.52)$ and $(\mathrm{OR}=0.54 ; 95 \% \mathrm{Cl}$ : $0.21-.097)$ respectively. Under-five children whose mothers had primary education also had fewer chances to be affected by stunt compared to the reference women with no formal education (OR $=0.58 ; 95 \% \mathrm{Cl}: 0.20-0.70$. Inline mothers with higher and secondary education were less likely affected by wasting and underweight compared to mothers with no formal education (see Table 3). Therefore, childhood malnutrition was found to be high in mothers and fathers with not educated formally. Different literatures said that educated societies are better informed about optional child care practices, have better practices in terms of feeding and childcare, uses health system and more allow to make decision [16, 17 and 18].

Malnutrition of under-five children also varied with wealth status of families. The odds of stunting among children aged under-five, those from middle and poor families, increased by 71 percent and 103 percent respectively as compared to those from rich families controlled for other variables in the model (OR = $1.71 ; 95 \% \mathrm{Cl}: 1.51-1.93)$ and $(\mathrm{OR}=2.03 ; 95 \% \mathrm{Cl}: 1.73-2.38)$. Children under category of rich family in wealth index were also positively allied to decreasing malnutrition under-five children. The study showed that under-five children from poor wealth status are a risk of malnutrition compared with children from rich households. This is consistent with other studies done in Ethiopia, Bangladesh and Nigeria [18, 19 and 20].

Age of under-five children is significantly associated with malnutrition status. For age group 0 to 20 months and 21 to 40 months, were 3.89 and 3.23 times more likely stunted comparing to reference category age group of 41 to $59(\mathrm{OR}=3.89$ : $95 \% \mathrm{Cl}$ : $3.44-4.40)$ and $(\mathrm{OR}=3.23 ; 95 \% \mathrm{Cl}$ : $2.86-3.68)$ respectively. It has been observed that malnutrition is strongly associated with age of children. As children's age increasing the malnutrition problem was decreasing. This is showing the probability of finish vaccine which reduces exposure to disease greater energy needs as child age increased [21,22 and 23]

There were differences in malnutrition status among the regions. The odd ratio of Afar region highly stunted compared to references region Tigray (OR $=1.53$; $95 \% \mathrm{Cl}: 1.17-2.00)$ while households lived in Amhara and Somali were no more differences comparing with Tigray region (OR $=1.07 ; 95 \% \mathrm{Cl}: 0.84-1.36)$ and

Loading [MathJax]/jax/output/CommonHTML/jax.js eholds lived in Somali, Afar and Amhara regions were more likely wasted than Tigray while others region were less

Page $7 / 13$ 
likely to be affected by wasting compared to reference region Tigray. Underweight under-five children lived except in Afar region, all were less likely exposed to underweight compared to Tigray region (Table 3). Malnutrition status also varied with place of residence. Societies of rural area were 66 and 70 percent times more likely stunted and underweight $(\mathrm{OR}=1.66 ; 95 \% \mathrm{Cl}$ : $1.33-1.97)$ and $(\mathrm{OR}=1.70 ; 95 \% \mathrm{Cl}$ : $1.42-2.03)$ respectively. Also 97 percent showed more likely wasted in rural compared to rural area $(\mathrm{OR}=1.97 ; 95 \% \mathrm{Cl}$ : $1.61-2.41)$. Under-five children from rural area were highly exposed to malnutrition than those from urban [24]. This may be due to fact that households residing in rural areas have low access of health care, safe water, sanitation facilities and unequal distribution of infrastructures. Another important reason associated with low nutritional status of rural households may be the higher levels of labor or workload among rural households compared with their urban area. Studies in Ghana and Ethiopia are similar to this study [25, 26]. Some studies in Nigeria and India contracting to this result those children in urban living are more prone to nutritional problem [27, 28]. Households who were had no at least once a week media access were 52 percent more likely stunted compared to who were had at least once a week media. Similarly under five children whose households not at all media access were more likely underweight and wasted compared to who were had at least once a week media access. 
Table 3

Multivariate model of estimates of individual and cluster level factors on malnutrition of under-five children in Ethiopia

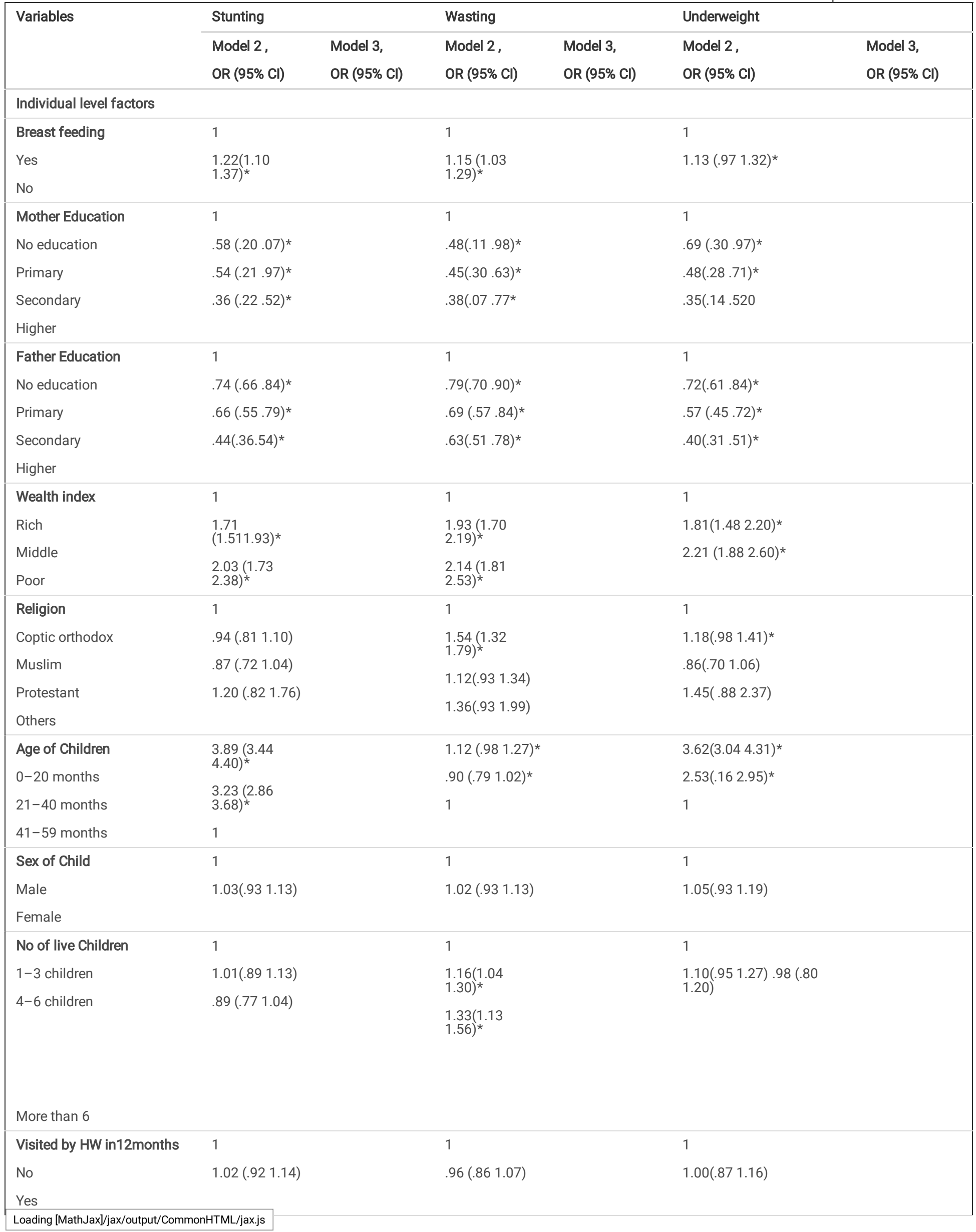




\begin{tabular}{|c|c|c|c|c|c|c|}
\hline \multirow[t]{2}{*}{ Variables } & \multicolumn{2}{|l|}{ Stunting } & \multicolumn{2}{|l|}{ Wasting } & \multicolumn{2}{|l|}{ Underweight } \\
\hline & $\begin{array}{l}\text { Model 2, } \\
\text { OR (95\% Cl) }\end{array}$ & $\begin{array}{l}\text { Model 3, } \\
\text { OR }(95 \% \mathrm{Cl})\end{array}$ & $\begin{array}{l}\text { Model 2, } \\
\text { OR (95\% Cl) }\end{array}$ & $\begin{array}{l}\text { Model 3, } \\
\text { OR (95\% Cl) }\end{array}$ & $\begin{array}{l}\text { Model 2, } \\
\text { OR (95\% Cl) }\end{array}$ & $\begin{array}{l}\text { Model 3, } \\
\text { OR ( } 95 \% \mathrm{Cl})\end{array}$ \\
\hline Marital Status & 1 & & 1 & & 1 & \\
\hline Single & $.74(.391 .40)$ & & $1.43(.782 .62)$ & & $1.23(.582 .65)$ & \\
\hline Married & $.54(.251 .17)$ & & $1.38(.642 .96)$ & & $.97(.382 .540$ & \\
\hline Widowed & $.63(.321 .240)$ & & $1.21(.632 .30)$ & & $.95(.422 .14)$ & \\
\hline \multicolumn{7}{|l|}{ Divorced } \\
\hline \multicolumn{7}{|l|}{ Community level } \\
\hline Region & & \multicolumn{2}{|l|}{1.} & \multicolumn{2}{|l|}{1} & 1 \\
\hline Tigray & & \multicolumn{2}{|l|}{$\begin{array}{l}1.53(1.17 \\
2.00)^{\star}\end{array}$} & \multicolumn{2}{|l|}{$1.25(.861 .81)^{\star}$} & $1.24(.861 .78)$ \\
\hline Afar & & \multicolumn{2}{|l|}{$1.07(.841 .36)$} & \multicolumn{2}{|l|}{$1.12(.781 .46)^{\star}$} & $1.08(.761 .53)^{\star}$ \\
\hline Amhara & & \multicolumn{2}{|l|}{$.62(.49 .79)^{\star}$} & \multicolumn{2}{|l|}{$.74(.58 .94)^{\star}$} & $.52(.38 .69)^{\star}$ \\
\hline Oromia & & \multirow{2}{*}{\multicolumn{2}{|c|}{$1.086(.85 .14)$}} & \multicolumn{2}{|l|}{$\begin{array}{l}2.10(1.61 \\
2.74)^{\star}\end{array}$} & $.62(.46 .84)^{*}$ \\
\hline Somali & & & & \multicolumn{2}{|l|}{$1.04(.781 .37)$} & $.76(.541 .10)$ \\
\hline Benishangul G & & \multicolumn{2}{|l|}{$.99(.751 .30)^{*}$} & \multirow{2}{*}{\multicolumn{2}{|c|}{$.62(.48 .79)^{\star}$}} & $.40(.30 .54)^{*}$ \\
\hline SNNP & & \multicolumn{2}{|l|}{$.64(.50 .82)^{\star}$} & \multirow{2}{*}{\multicolumn{2}{|c|}{$1.28(.951 .72)$}} & $.65(.45 .92)^{*}$ \\
\hline Gambela & & \multicolumn{2}{|l|}{$.46(.35 .61)^{\star}$} & & & $.50(.35 .72)^{*}$ \\
\hline Harari & & \multicolumn{2}{|l|}{$.58(.43 .78)^{\star}$} & \multicolumn{2}{|l|}{$.81(.591 .10)$} & $.30(.21 .43)^{*}$ \\
\hline Addis Ababa & & \multicolumn{2}{|l|}{$.39(.28 .55)^{\star}$} & \multicolumn{2}{|l|}{$.52(.37 .72)^{*}$} & $75(51111)$ \\
\hline Dire Dawa & & \multicolumn{2}{|l|}{$.72(.52 .98)^{\star}$} & \multicolumn{2}{|l|}{$\begin{array}{l}1.57(1.12 \\
2.20)^{*}\end{array}$} & 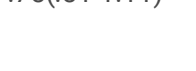 \\
\hline Place of residence & & \multicolumn{2}{|l|}{1} & 1 & & 1 \\
\hline Urban & & $\begin{array}{l}1.66(1.39 \\
1.97)^{*}\end{array}$ & & $\begin{array}{l}1.70(1.42 \\
2.03)^{*}\end{array}$ & & $\begin{array}{l}1.97(1.61 \\
2.41)^{\star}\end{array}$ \\
\hline Rural & & & & & & \\
\hline Source of Water & & 1 & & 1 & & 1 \\
\hline Un protected water & & $1.05(.941 .17)$ & & $.96(.861 .10)$ & & $1.10(.921 .22)$ \\
\hline Protected water & & & & & & \\
\hline Media Access & & 1 & & 1 & & 1 \\
\hline $\begin{array}{l}\text { At least once a week Not at } \\
\text { all }\end{array}$ & & $\begin{array}{l}1.52(1.32 \\
1.74)^{\star}\end{array}$ & & $\begin{array}{l}1.54(1.33 \\
1.78)^{\star}\end{array}$ & & $\begin{array}{l}1.36(1.14 \\
1.64)^{\star}\end{array}$ \\
\hline Electricity & & 1 & & 1 & & 1 \\
\hline No & & $.97(.861 .100$ & & $.93(.821 .05)$ & & $1.03(.891 .19)$ \\
\hline Yes & & & & & & \\
\hline$\delta_{0}^{2}=\operatorname{var}\left(U_{o j}\right)$ & $.36(.28 .46)$ & $.20(.14 .27)$ & $.43(.31 .59)$ & $.19(.13 .27)$ & $.41(.32 .52)$ & $.17(.11 .28)$ \\
\hline Deviance-based & 147.25 & 79.92 & 84.08 & 27.55 & 173.56 & 54.84 \\
\hline
\end{tabular}

*significant of P value; OR: Odds Ratio, Cl: Confidence Interval

Model 2- individual levels factors include in the model; Model 3- cluster level factors included in the model

Conclusion

Spatial variability of malnutrition of under-five children across survey clusters and regions were witnessed. Child age in months, breastfeeding at a time,

Loading [MathJax]/jax/output/CommonHTML/jax.js index showed a statistical significant association with child malnutrition. It has been observed that malnutrition is 
strongly associated with age of children. Childhood malnutrition was highly found in mothers and fathers with no education formally. Children under category of rich family in wealth index were also positively allied to decreasing malnutrition under-five children.

In Ethiopia under-five children who lived rural were more likely to be affected by malnutrition than who lived in urban area. Among regions, children living in Tigray, Amhara and Somali were more stunted than other regions. Children living in Somali and Afar were more wasted. And children in Somali and Afar showed to be more underweight. While children living in Addis Ababa showed lowest malnourished. The results of the study manifest regional differences in under-five children malnutrition and its determinants. This may be associated with limited healthcare facilities, dietary practices, inequality in the distribution of service and resources. Source of water and accessibility of electricity were not statistically significant at cluster level.

The existence of variances of constant term in the empty -model showed that the existence of variation in malnutrition among under-five children in Ethiopia. Making inclusion of predictor variables to the multilevel modeling indicated that factors had impacts on malnutrition making variation among regions

Enhance educational activities regarding nutritional and health services using media, health extension workers and health institutions in Ethiopia. Governmental and non-governmental organizations' programs should focus on women and children particularly those who need supports.

\section{Abbreviations}

WHO: World Health Organization; EDHS:Ethiopian Demographic and Health Survey; SNNP:South of Nation and Nationalism of Populations; ICC:Intra class correlation; OR:Odd ratio; Cl:Confidence interval.

\section{Declarations}

Acknowledgements: this work was supported (funded) by Ambo University. We are grateful to all individuals and institutions for providing the necessary information for this work.

Authors' Contribution: RL raised the idea of the research and planned and proposed the research methodology. RL and GA carried out analyzed of data, and wrote the paper. RL, AT and GA interpreted the results and edited the final manuscript. RL had primary responsibility for the final content. All authors read and contributed to the reviewing the analysis of the data, the designing of the manuscript, and the agreement of the final manuscript.

Availability of data: Data of the study are available with the author as per request.

Competing interests: The authors declare have no competing interests.

Ethical approval and consent to participate: Ethical approval and permission was obtained from ethical committee of Ambo University.

\section{References}

1. 1. World Health Organization, Nutrition Land Information System Country profile Indicators: Interpretation and Guide, Geneva, 2010.

2. 2. Black RE, Allen LH, Bhutta ZA, Caulfied LE, Deonis M, and Ezzati M: Maternal and Child under nutrition: Global and regional exposures and health consequences. Lancet, 2008; 371: $243-60$.

3. 3. World Health Organization, Child Growth Standards: Length/Height for Age, Weight for Age, Weight for Height and Body Mass Index for Age: Methods and Development, Geneva, Switzerland, 2006.

4. 4. Jennifer Bryce, Denise Cothinho, lan Darnton-Hill, David Pelletier, Per Pinstrup-Anderse: maternal and child under nutrition: effective action at national level, 2008: DOI: 10.1016/S0140-6736(07), 61694-8.

5. 5. Central Statistical Agency and ORC Macro: Ethiopian Demographic and Health Survey. Addis Ababa, Ethiopia; Calverton, Maryland, USA 2016.

6. 6. Ethiopian Public Health Institute (EPHI) and ICF. Ethiopia Mini Demographic and Health Survey 2019: Key Indicators. Rockville, Maryland, USA: EPHI and ICF.

7. 7. Ngianga-BakwinKandala, Tumwaka P Madungu, Jacques BO Emina, Kikhela PD Nzita and Francesco P Cappuccio: Malnutrition among children under the age of five in the Democratic Republic of Congo (DRC): Does geographic location matter? BMC Public Health, $2011: 11 ; 261$.

8. 8. Pongou R, Ezzati M, Salomon JA: Household and Community Socioeconomic and Environmental Determinants of Child Nutritional Status in Cameroon. BMC, Public Heath, 2006; 6: 98; 19.

9. 9. Assefa T, Belachew T, Ayalew T, Deribew A. Mothers' Health Care Seeking Behavior for Childhood Illnesses in Derra District, North shoa Zone, Oromia Regional State, Ethiopia. Ethiopian Journal of Health Development, 2008; 18(3): 90-93.

10. 10. Bishwakarma Ramu: Spatial Inequality in Child Nutrition in Nepal: Implications of Regional Context and Individual/Household Composition; Dissertation of Doctor of Philosophy, 2011.

11. 11. Cressie Nac. Statistics for Spatial Data, New York, Wiley, 1993.

12. 12. Snijders T. A.B. and Roel J. Bosker. Multilevel Analysis. An introduction to basic and advanced multilevel modeling (2nd Edition). London, Sage.Thum, 2012.

13. 13. Barun Kanjilal, Papiya Guha Mazumdar, Moumita Mukherjee, Hafizur Rahman: Nutritional status of children in India: Household Socio-economic condition as the contextual determinant, 2010; 19(9).

Loading [MathJax]/jax/output/CommonHTML/jax.js 
14. 14. Sunguya BF, Poudel KC, Mlunde LB, Urassa DP, Yasuoka J, Jimba M. Poor nutrition status and associated feeding practices among HIV-positive children in a food secure region in Tanzania: a call for tailored nutrition training. Plos one, 2014; 9(5).

15. 15. Mukabutera A, Thomson DR, Hedt-Gauthier BL, Basinga P, Nyirazinyoye L, Murray M. Risk factors associated with underweight status in children under five: An analysis of the Rwanda Demographic Health Survey (RDHS). BMC Nutrition, 2016; 2(1).

16. 16. Kimani-Murage EW, Muthuri SK, Oti SO, Mutua MK, Van De Vijver S Kyobutungi C. Evidence of A Double Burden of Malnutrition in Urban Poor Settings in Nairobi, Kenya. PLOS One. DOI: 2015; 10.137.

17. 17. Neima Endris, HenokAsefa, and LamessaDube: Prevalence of Malnutrition and Associated Factors among Children in Rural Ethiopia: Hindawi, BioMed Research International, 2017; 7(1), doi.org/10.1155/2017/6587853.

18. 18. Keya Roy, Aparajita Dasgupta, Nivedita Roychoudhury, Lina Bandyopadhyay, Shamita Mandal, Bobby Paul: Assessment of under nutrition with composite index of anthropometric failure (CIAF) among under-five children in a rural area of West Bengal, India, 2018; 5(4):1651-1656.

19. 19. R.E Kalu and K.D Etim: Factors Associated with Malnutrition among under-five Children in Developing Countries: A Review. Global Journal of Pure and Applied Sciences, 2018; 24: 69-74.

20. 20. Abeshu MA, Lelisa A, Geleta B. Complementary feeding: review of recommendations, feeding practices, and adequacy of homemade complementary food preparations in developing countries-lessons from Ethiopia. Frontiers in nutrition, 2016; 3:41.

21. 21. Md. Nure Alam Siddiqi, Md. Nuruzzaman Haque, Md. Abdul Goni: Malnutrition of Under-Five Children: Evidence from Bangladesh, Asian Journal of Medical Sciences (2011) 113-119.

22. 22. ZerihunYohannes, Mossa Endris and Adey Belete: Determinants of Nutritional Status among Children Under five age in Ethiopia: A Further Analysis of the Ethiopian Demographic and Health Survey (EDHS) 2016 Data. doi: http://dx.doi.org/10.1101/698308.

23. 23. Fantay Gebru, Mekonnen Haileselassie, Haftom Temesgen, OumerS eid and Afework Mulugeta, Determinants of Stunting among Under-Five Children in Ethiopia: A Multilevel Mixed effects Analysis of 2016 Ethiopian Demographic and Health Survey Data; BMC Pediatrics, $2019 ; 19: 176$.

24. 24. Demewoz Haile, Dabere Nigatu, Ketema Gashaw and Habtamu Demelash. Height for age Z score and cognitive function are associated with Academic performance among school children aged 8-11 years old, 2016; 17 (74).

25. 25. Adekanmbi VT, Uthman OA, Mudasiru OM. Exploring Variations In Childhood Stunting In Nigeria Using League Table, Control Chart And Spatial Analysis. BMC Public Health, 2013; 13:361.

26. 26. Sebsibe T. and Yinges A., "Urban-rural differentials in child under nutrition in Ethiopia”, International Journal of Nutrition and Metabolism, 2015; 7(1): 15-23.

27. 27. Boah M, Azupogo F, Amporfro DA, Abada LA: The epidemiology of under nutrition and its determinants in children under five years in Ghana, 2019. PLoS ONE 14(7): e0219665. https://doi. org/10.1371/journal.pone.0219665

28. 28. Yadav, A., Ladusingh, L., \& Gayawan, E. (2015). Does a geographical context explain regional variation in child malnutrition in India? Journal of Public Health, 23(5), 277-287. https://doi.org/10.1007/s10389-015-0677-4.

\section{Figures}

Spatial distribution of Wasting of Under five children in Ethiopia

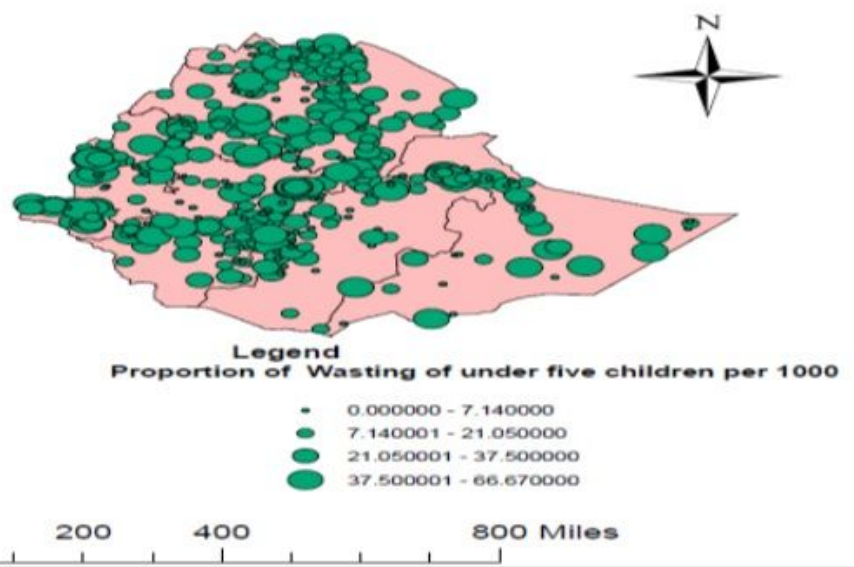

Figure 1

presents observed distribution of stunting, underweight and wasting the 2019 
a)

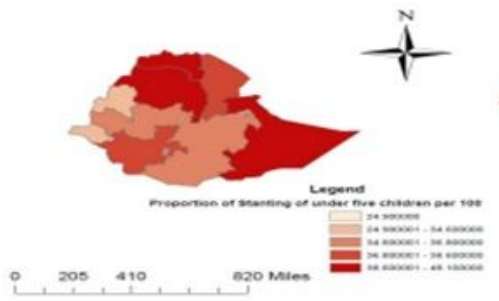

c)

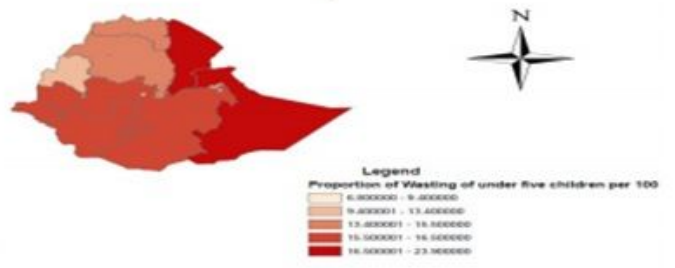

인, $205,410,820$ Miles

Figure 2.Spatial distribution of child stunting (a), underweight (b) and wasting (c) among under five children

Figure 2

Spatial clustering of stunting, wasting and underweight among under five children 